\title{
Vitamin D Levels and Bone Mineral Density in Inborn Errors of Metabolism Requiring Specialised Diets
}

\author{
Asburce Olgac, Asli Inci, Ilyas Okur, Fatih Ezgu, Gursel Biberoglu and Leyla Tumer \\ Department of Pediatrics, Division of Pediatric Metabolism and Nutrition, Gazi University School of Medicine, Turkey
}

\begin{abstract}
Objective: To evaluate vitamin $\mathrm{D}$ levels and bone mineral density in patients with dietary limitations due to inborn errors of metabolism (IEM) and its correlation with diets.

Study Design: Retrospective study.

Place and Duration of Study: Department of Pediatrics, Division of Pediatric Metabolism and Nutrition, Gazi University Hospital, Turkey, from March to Semtember 2016.

Methodology: The study is a retrospective review of 115 patients. Information about vitamin D status, bone mineral density (BMD) measurement and anthropometric parametres were collected. Patients were divided into two major groups, receiving protein-restricted diets $(n=83)$ and lactose-restricted diets $(n=32)$. Data of 110 healthy children were used as the control group.

Results: Mean vitamin D level of patients with special diets $28.1 \pm 14.9 \mathrm{ng} / \mathrm{ml}$ while mean level of healthy controls was $26.6 \pm 12.27 \mathrm{ng} / \mathrm{ml}$. Levels of $26.8 \%(\mathrm{n}=26 / 97)$ patients were found to be deficient and $34 \%(n=33 / 97)$ were found to be insufficient. No statistically significant differences were found between vitamin D levels and BMD of patients and healthy controls. BMD was not influenced by vitamin D levels.

Conclusion: Low BMD may be encountered in IEM, independent of vitamin D levels and revision of diet for adequacy of essential nutrients; and follow-up for dietary compliance is inevitable.
\end{abstract}

Key Words: Vitamin D, Bone health, Inborn errors of metabolism, Galactosemia, Glycogen storage disorders, Diet.

How to cite this article: Olgac A, Inci A, Okur I, Ezgu F, Biberoglu G, Tumer L. Vitamin D levels and bone mineral density in inborn errors of metabolism requiring specialised diets. J Coll Physicians Surg Pak. 2019; 29(12):1207-1211.

\section{INTRODUCTION}

Vitamin $\mathrm{D}$ is a pro-hormone formed from a metabolite of cholesterol, involved in the regulation of calcium and phosphorus metabolism and plays a pivotal role in bone health. Factors such as age, gender, race/ethnicity, adiposity will also affect vitamin D status. Serum 25hydroxyvitamin $D[25(\mathrm{OH}) \mathrm{D}]$ is currently considered the best marker of vitamin $D$ status. ${ }^{1}$ Sunlight is the best source of vitamin $D$, as its presence in food is limited. Vitamin $D$ deficiency is mainly caused by insufficient sun exposure or low dietary intake.1,2

Vitamin $\mathrm{D}$ deficiency and bone diseases may also be seen in children and adults with inborn errors of metabolism (IEM) who consume specialised diets that restrict natural food sources of vitamin D and calcium, or due to low sun exposure related to physical disabilities, the use of special drugs (e.g. anticonvulsants), inflammation and genetic factors. ${ }^{2}$ The pathophysiology of diminished bone

Correspondence to: Dr. Asburce Olgac, Department of Pediatrics, Division of Pediatric Metabolism and Nutrition, Gazi University School of Medicine, Turkey

E-mail: mabolgac@yahoo.com

Received: December 08, 2018; Revised: May 25, 2019; Accepted: June 14, 2019 mineral density (BMD) in IEM has not been extensively studied. 3

Although many subtypes of IEM require different kinds of diets, one of the major factor that predispose patients to insufficient calcium intake, hence osteopenia, is the restriction of dairy products and other high protein foods. ${ }^{4}$ For example, amino acid metabolism disorders necessitate a protein-restricted diet that should be carried on for life. For most amino acidopathies including organic aciduras, phenylketonuria, tyrosinemia etc., dietary intervention should be started at the earliest stage with almost total absence of any natural proteinsource, including dairy amd animal products with respect to the underlying IEM with the help of proteinfree, or low protein foods and certain amino acid mixtures.

Another subtype of IEM that requires severe dietary restriction is galactosemia, which is an inherited galactose metabolism disorder caused by the deficiency of galactose-I-phosphate-uridyltransferase (GALT) enzyme, that is responsible for the conversion of galacatose-Iphosphate to uridine-diphophate (UDP)-galactose. ${ }^{3}$ If not treated in the early neonatal phase, the disease may cause a neonatal toxic syndrome with cataracts and liver failure, with long-term complications including neurological deficits and infertility. Treatment consists of acute 
restriction of galactose (with lactose-free formulas in the neonatal period, and elimination of dairy products afterwards). Patients with galactosemia may be at risk for osteoporosis due to dietary deficiencies secondary to galactose restriction (mainly dairy products), since milk products are considered to be the best source of dietary calcium. ${ }^{3}$

Ingredients of the special formulas used in children with IEM requiring specialised diet are usually vitamin D fortified and contain higher amount of vitamin D levels when compared to infant formulas and breast milk. ${ }^{5}$ Compliance to the recommended daily allowance (RDA) of daily protein intake of children with specialise diets is essential in order to prevent growth retardation and ensure bone health. 3,4

The objective of this study was to determine the serum 25(OH)D concentrations and BMD in children with specialised diets due to IEM; and the the relationship of diets with several parameters related to bone health. The second objective was to correlate $25(\mathrm{OH}) \mathrm{D}$ status with BMD and growth parametres.

\section{METHODOLOGY}

The study was a retrospective review of 115 patients with IEM on specialised diets, carried out in Gazi University Hospital from March to September 2016. Information about diets, vitamin D status and BMD measurement were collected retrospectively. The Ethical Commitee of Gazi University approved the study.

The records of patients being followed up in our clinic were retrospectively reviewed. Patients with diseases with bone involvement or causing any effect on nutritional status (e.g. malabsorbtion), patients without dietary compliance, using drugs that interfere with vitamin $D$ absorbtion and bone metabolism, and who receive vitamin D replacement were excluded. Demographic data (age, gender, Tanner stage, ethnicity), anthropometric measures (weight and height), serum 25(OH)D levels (most recent one), date of blood drawal, BMD scores obtained with lumbar and femoral neck DEXA scan and diets were recorded. The vitamin $D$ levels and BMD scores of 110 age and sex matched controls without any dietary restriction were also searched electronically.

Patients were classified into 2 major groups of proteinrestricted diets and dairy-products (lactose) restricted diets according to the dietary limitations because of underlying IEM. The diagnoses of patients according to the latest classification of Society for the Study of Inborn Errors of Metabolism (SSIEM), are listed in Table I (www.ssiem.org).

Serum 25(OH)D levels analysed by a high pressure liquid chromatography tandem mass spectrometry (HPLC-MS/MS) method were recorded. The values for vitamin $\mathrm{D}$ deficiency and insufficiency were determined according to the criteria of European Society of Paediatric Gastroenterology, Hepatology and Nutrition (ESPGHAN). ${ }^{6}$ Values below $20 \mathrm{ng} / \mathrm{ml}(50 \mathrm{nmol} / \mathrm{L})$ were accepted as deficiency and values between 20 and 29.9 $\mathrm{ng} / \mathrm{ml}(50-74.9 \mathrm{nmol} / \mathrm{L})$ as vitamin $D$ insufficiency. The cut-off for normal vitamin $D$ levels were $\geq 30 \mathrm{ng} / \mathrm{ml}(\geq 75$ $\mathrm{nmol} / \mathrm{L})$.

BMD of the lumbar spine and hip was determined by dualenergy X-ray absorptiometry using LUNAR-DPX technology. BMD could be applied to children above age 4 , since $Z$ scores could only be obtained in patients above this age. In children, a $Z$ score that represents age and sexmatched normative values were used to determine BMD. The evaluation was based on densitometric criteria set by the World Health Organization (WHO) for the lumbar and femoral neck DEXA scan. According to the International Society for Clinical Densitometry Official Position definition, a Z-score of -2.0 or lower was defined as "below the expected range for age," and a Z-score above -2.0 was regarded as "within the expected range for age".7

Statistical analyses were performed in SPSS for Windows V. 11.5. Descriptive statistics were used to examine $25(\mathrm{OH}) \mathrm{D}$. Mean \pm standard deviations were calculated for continuous variables and median interquartile range (IQR) for non-parametric continuous variables. Frequencies with percentages were given for categorical variables. Shapiro-Wilks was performed to test normality. Vitamin $D$ concentration (continuous variable) was compared between groups by using the non-parametric Mann-Whitney U-test (for two groups) or Kruskal-Wallis (One-Way Anova) for independent variables with more than two groups. Chi-square test was also performed to analyse categorical variables. Spearman-Rank correlation analysis was used to examine the association among vitamin $D$ status and several factors. Results were considered significant at $p<0.05$.

\section{RESULTS}

The data of 115 patients, including 63 males (55\%) and 52 females $(45 \%)$ were evaluated. Mean age of patients was $5.55 \pm 4.47$ years. Eighty-three patients received protein restricted diets $(72 \%)$ and and 32 received galactose restricted diets (27\%). Mean age of children consuming protein restricted diet was found to be 5.74 \pm 3.83 years (median: 5) and mean age of children consuming lactose restricted diets was $5.07 \pm 3.97$ years (median: 4.25). No differences of age $(p=0.133)$ and gender $(0=0.855)$ were found between patients receiving diets and the control group. Diagnoses of patients included in the study is shown in Table I.

Although serum $25(\mathrm{OH}) \mathrm{D}$ analysis and DEXA scanning for BMD are routinely performed in our clinic in children with IEM, some patients had missing data due to various 
Table I: Diagnoses of patients enrolled in the study.

\begin{tabular}{l|c|c}
\hline Diagnosis & $\mathrm{n}$ & $\%$ \\
\hline Amino acid metabolism disorders & 83 & 72 \\
Phenylketonuria & 36 & 31.5 \\
Organic acidurias & 27 & 23.5 \\
Urea cycle disorders & 10 & 8.5 \\
Tyrosinemia & 5 & 4.5 \\
Alkaptonuria & 2 & 1.5 \\
Homocystinuria & 3 & 2.5 \\
\hline Carbohydrate metabolism disorders & 32 & 28 \\
Glycogen storage disease type 1 & 16 & 14 \\
Galactosemia & 16 & 14 \\
\hline
\end{tabular}

Table II: Mean 25(OH)D and BMD scores of groups.

\begin{tabular}{l|c|c}
\hline Diet $(\mathrm{n})$ & Mean 25(OH)D, ng/ml $( \pm \mathrm{SD})$ & BMD \\
\hline Low-protein (83) & $29.35 \pm 15.1(27.0)$ & $-1.1(1.7)$ \\
Lactose-free (32) & $25.1 \pm 14.2(22.3)$ & $-0.25(2.3)$ \\
Healthy controls (110) & $23.27 \pm 12.1(21.05)$ & $-0.75(1.7)$ \\
\hline $\mathrm{p}$ & 0.193 & 0.267 \\
\hline
\end{tabular}

problems encountered in record keeping (e.g. inaccecibility of former records).

25(OH)D levels of 97 out of 115 patients were avaliable. No significant correlations were found between age $(p=0.170)$, gender $(p=0.620)$ and time of blood drawal $(p=0.573)$ with $25(\mathrm{OH}) \mathrm{D}$ levels. Mean $25(\mathrm{OH}) \mathrm{D}$ level was $28.14 \pm 14.9 \mathrm{ng} / \mathrm{ml}$ among patients with specialised diets. Levels of $26 / 97(26.8 \%)$ patients were found to be deficient $(<20 \mathrm{ng} / \mathrm{ml})$ and $33 / 97(34 \%)$ were found to be insufficient $(20-29.9 \mathrm{ng} / \mathrm{ml})$. Mean $25(\mathrm{OH}) \mathrm{D}$ level of healthy controls was $26.6 \pm 12.27 \mathrm{ng} / \mathrm{ml}$. The rate of deficiency and insufficiency in the control group was $25.4 \%(15 / 59)$ and $35.6 \%$ (21/59), respecitvely. No statistically significant differences were found between vitamin $D$ levels of patients and healthy controls $(p=0.633)$. 25 $(\mathrm{OH}) \mathrm{D}$ levels of both diet groups were comparable (29.3 \pm 15.1 , median: $27 \mathrm{ng} / \mathrm{ml}$ in the protein-restricted diet group and $25.15 \pm 14.2$, median: $22.3 \mathrm{ng} / \mathrm{ml}$ in the galactose restricted diet group, $\mathrm{p}=0.193$ ).

BMD scores of 70 out of 115 patients were available $(60.8 \%)$, where $18 / 70(25.7 \%)$ were below the expected range for age ( $<2 \mathrm{SD})$. Median value of BMD scores of patients with specialised diets was found to be -1.0 (IQR: $1.8)$, while the median value of healthy controls was -0.4 (IQR: 0.9). BMD scores among patients with specialised diets were comparable to healthy controls $(p=0.082)$. The median BMD scores of protein-restricted and galactose-restricted groups were -1.32 (IQR: 1.7) and -0.25 (IQR:2.3), respectively. BMD values also did not show any difference between different diet groups $(p=0.267$, Table II).

Anthropometric measures of 112 patients were available where $11(9.8 \%)$ showed growth retardation (weight and height under the 3rd centile). No differences of growth parameters were detected between healthy controls and patients with dietary limitations $(p=0.914)$.

Among patients with vitamin $D$ deficiency, $7.6 \%(n=2 / 26)$ showed growth retardation. Mean 25(OH)D levels of patients with and without growth retardation were 31.1 $\pm 18.6 \mathrm{ng} / \mathrm{ml}$ and $27.5 \pm 14.4 \mathrm{ng} / \mathrm{ml}$, respectively. The relationship between Vitamin $D$ status and growth retardation was not statistically significant $(p=0.503)$.

Among patients with osteopenia, 38\% $(n=7 / 18)$ showed growth retardation. The median of BMD scores of patients with and without growth retardation were -4.9 and -0.6 , respectively. Relationship between osteopenia and growth retardation was found significant ( $p<0.001)$.

In this study group, osteopenia was more frequent among patients with low $25(\mathrm{OH}) \mathrm{D}$ levels. Thirty-five percent $(13 / 37)$ of patients with vitamin D deficiency showed osteopenia. The median BMD score of patients with normal vitamin D levels were $-0.9(I Q R: 1.6) \mathrm{ng} / \mathrm{ml}$, while the mean BMD score of patients with vitamin $D$ deficiency was $-1.3(I Q R: 2.6) \mathrm{ng} / \mathrm{ml}$. Despite these findings, the statistical analysis of 25(OH)D and BMD relationship did not show any statistical significance $(p=0.693)$.

\section{DISCUSSION}

This study aimed to determine the effects of specialised diets on 25(OH)D status and BMD in patients with various types of IEM that require specialised diets. Patients included in this study were divided into two groups, amino acid metabolism disorders (consuming low-protein diet) and carbohydrate metabolism disorders (consuming mainly galactose-restricted diets).

Studies performed on healthy children have reported vitamin $\mathrm{D}$ deficiency to be $30-51.8 \%$ and insufficiency to be $15-20.7 \% .8,9$ Although, generally being a sunny country, the prevalance of vitamin $D$ deficiency is high among children, despite the nationwide vitamin $D$ supplementation programme, started in 2005 , which consists of 400 IU/day vitamin D supplementation starting from birth until the end of first year. ${ }^{8}$ The rate of vitamin $D$ deficiency in our study group consuming specialised diets, was similar to the levels of healthy controls. Also, 25(OH)D levels of both groups with specialised were comparable, which can be due to several factors. First of all, the supplementary dietary products that patients which specialised diets consume daily (amino acid mixtures or lactose-free formulas), also provide vitamins, minerals and trace elements, and permit daily energy and nutrients requirements. ${ }^{11}$ Those supplementary products are vitamin $\mathrm{D}$ fortified and contain approximately $18 \mu \mathrm{g}$ vitamin $\mathrm{D}$ in $100 \mathrm{gr}$ of product. Secondly, since patients included in the study were physically active, the time that these patients spend outside; hence, sun exposure can be expected to be similar to healthy children, which definitely contributed to their 25(OH)D levels. Although the 
supplementary products are vitamin D fortified, patients with specialised diets may still be at risk of osteopenia, since vitamin $D$ deficiency is not the only factor leading to defective bone metabolism.

In this study population, BMD of patients with specialised diets and healthy controls were comparable, and also no difference between BMDs of patients consuming protein-restricted diets vs. dairy product-restricted diets could be detected. The effects of specialised diets on BMD have been previously reported in many studies. ${ }^{10-}$ 18 Although one of the major factors for low BMD in patients consuming medical food based diets is the low intake of essential nutrients, ${ }^{11}$ diets of patients in the clinic are closely monitored for the content of diet to meet RDA's for calcium, magnesium, zinc were met in all patients. We think that the major reason for comparable levels of BMDs of patients with diets with healthy controls may be the multifactorial nature of ethiological determinants of BMD status, such as weight, muscle mass, physical activity capacity, daily calcium intake and underlying diseases, as shown in many studies. 13 Similar to the vitamin $D$ levels of patients, BMD's levels of patients did not show any difference than healthy controls, that may be due to the physical activity levels of patients, since children with physical disabilities were excluded from the study.

BMD of patients with growth retardation was determined to be lower, when compared to patients with normal antropometric parameters, similar to previous studies that have evaluated the commection between body composition and bone strength, 15 suggesting the importance of screening for osteoporosis in children with growth retardation.

Many studies in literature, including meta-analyses, have evaluated the relationship of $25(\mathrm{OH}) \mathrm{D}$ levels and BMD of children with IEM consuming protein-restricted diets (mainly phenylketonuria), and could not detect any significant correlation. ${ }^{16-20}$ Moreover, in this study, no significatant relationship was detected between vitamin $D$ levels and BMDs of patients receiving specialised diets. Although the effect of vitamin $D$ on bone health is well known, BMD is influenced by many factors including genetic, environmental and endocrine factors. Especially for many types of IEM, there is a real need for analysing and regulating potential contributors to the bone loss observed in these diseases.

This study has several limitations. Although patient numbers were adequate, lack of availability of all parametres evaluated, constrained our study. Moreover, number of patients could be expanded by including other kind of specialised diets used in IEM's i.e. low-fat diets or ketogenic diets, Although only patients with dietary compliance were included in the study, daily calcium and natural proten intakes, which are important factors influencing BMD, could not be standardised, which is a major limitation. Evaluation of bone health could be performed in a broader spectrum in respect of biochemical markers.

This study aimed to evaluate vitamin D levels of patients with certain IEM with dietary restrictions and its relationship with several factors associated with bone health. Since the effect of vitamin $D$ on bone health is well known, vitamin $D$ supplementation is obligatory in the follow-up of these patients. Attention should be given, especially to patients with growth retardation, and supportive care including diet modification, physiotherapy and promotion of outdoor activities to ensure sun exposure should be maintained. Further studies focusing on specific types of IEM's including higher number of patients with a broader spectrum of patients to include different kinds of dietary modifications is required. Furthermore, additional supplementation other than vitamin D should be considered in patients with IEM with dietary restrictions (also to the healthy population), along with calcium supplementation.

\section{CONCLUSION}

Low BMD may be encountered in IEM, independent of vitamin $D$ levels, and revision of diet for adequacy of essential nutrients; and follow-up for dietary compliance is inevitable.

\section{ETHICAL APPROVAL:}

Ethical approval of this study was obtained from Gazi University Ethics Committee prior to initiation of the research work.

\section{PATIENTS' CONSENT:}

Informed consent was obtained from patients to publish the data concerning this study.

\section{CONFLICT OF INTEREST:}

Authors declared no conflict of interest.

\section{AUTHORS' CONTRIBUTION:}

AO: Conception and design of work, the analysis and interptretation of data, drafting and revision of work, final approval of the version to be published, aggreement to be accountable for all aspects of the work in ensuring that quetions related to the accuracy or integrity of any part of the work are approprately investigated and resolved.

Al: Conception of work, drafting of work, final approval of the version to be published, aggreement to be accountable for all aspects of the work in ensuring that quetions related to the accuracy or integrity of any part of the work are approprately investigated and resolved.

IO: Design of work, revision of work, final approval of the version to be published, aggreement to be accountable for all aspects of the work in ensuring that quetions related to the accuracy or integrity of any part of the work are approprately investigated and resolved. 
FE: Conception of work, the analysis and interptretation of data revision of work, final approval of the version to be published, aggreement to be accountable for all aspects of the work in ensuring that quetions related to the accuracy or integrity of any part of the work are approprately investigated and resolved.

GB: Design of work, interptretation of data, revision of work, final approval of the version to be published, aggreement to be accountable for all aspects of the work in ensuring that quetions related to the accuracy or integrity of any part of the work are approprately investigated and resolved.

LT: Conception of work, the analysis and interptretation of data revision of work, final approval of the version to be published, aggreement to be accountable for all aspects of the work in ensuring that quetions related to the accuracy or integrity of any part of the work are approprately investigated and resolved.

\section{REFERENCES}

1. Moon RJ, Harvey NC, Davies JH, Cooper C. Vitamin D and skeletal health in infancy and childhood. Osteoporos Int 2014; 25:2673-84

2. Reid IR. What diseases are causally linked to vitamin $D$ deficiency? Arch Dis Child 2016; 101:185-9.

3. Panis B, Forget PP, van Kroonenburgh MJ, Vermeer C, Menheere PP, Nieman FH, et al. Bone metabolism in galactosemia. Bone 2004; 35:982-7.

4. Geiger KE, Koeller DM, Harding CO, Huntington $\mathrm{KL}$, Gillingham MB. Normal vitamin D levels and bone mineral density among children with inborn errors of metabolism consuming medical food-based diets. Nutr Res 2016; 36:101-8.

5. Acosta PB. Nutritional management of patients with Inherited metabolic disorders. Jones and Bartlett Publishers, 2010.

6. Braegger C, Campoy C, Colomb V, Decsi T, Domellof M, Fewtrell $\mathrm{M}$, et al. Vitamin $\mathrm{D}$ in the healthy European pediatric population. J Pediatr Gastroenterol Nutr 2013; 56:692-701.

7. Lewiecki EM, Gordon CM, Baim S, Leonard MB, Bishop NJ, Bianchi ML, et al. International society for clinical densitometry 2007 - adult and pediatric official positions. Bone 2008; 43: 1115-21.

8. Ozkan B, Doneray H, Karacan M, Vançelik S, Yildirim ZK,
Ozkan A, et al. Prevalence of vitamin D deficiency rickets in the eastern part of Turkey. Eur J Pediatr 2009; 168:95-100.

9. Andiran N, Çelik N, Akça H, Dogan G. Vitamin D deficiency in children and adolescents. J Clin Res Pediatr Endocrinol 2012; 4:25-9.

10. Feillet $F$, Agostoni $C$. Nutritional issues in treating phenylketonuria. $J$ Inherit Metab Dis 2010; 33:659-64.

11. Lage S, Bueno M, Andrade F, Prieto JA, Delgado C, Legarda M, et al. Fatty acid profile in patients with phenylketonuria and its relationship with bone mineral density. $J$ Inherit Metab Dis 2010; 33(Suppl 3):363-71.

12. Burda P, Hochuli M. Hepatic glycogen storage disorders: What have we learned in recent years? Curr Opin Clin Nutr Metab Care 2015; 18:415-21.

13. Hill TR, Cotter AA, Mitchell S, Boreham CA, Dubitzky W, Murral L, et al. Vitamin D status and parathyroid hormone relationship in adolescents and its association with bone health parameters: Analysis of the Northern Ireland Young Heart's Project. Osteoporos Int 2010; 21:695-700.

14. Saggese G, Vierucci F, Boot AM, Czech-Kowalska J, Weber G, Camargo CA Jr, et al. Vitamin D in childhood and adolescence: An expert position statement. Eur J Pediatr 2015; 174:565-76.

15. Farr JN, Amin S, LeBrasseur NK, Atkinson EJ, Achenbach SJ, McCready LK, et al. Body composition during childhood and adolescence: Relations to bone strength and microstructure. J Clin Endocrinol Metab 2014; 99:4641-8.

16. de Groot MJ, Hoeksma M, van Rijn M, Slart RH, van Spronsen FJ. Relationships between lumbar bone mineral density and biochemical parameters in phenylketonuria patients. Mol Genet Metab 2012; 105:566-70.

17. Demirdas S, Coakley KE, Bisschop PH, Hollak CE, Bosch AM, Singh $\mathrm{RH}$. Bone health in phenylketonuria: A systematic review and meta-analysis. Orphanet J Rare Dis 2015; 10:17.

18. Mendes AB, Martins FF, Cruz WM, da Silva LE, Abadesso CB, Boaventura GT. Bone development in children and adolescents with PKU. J Inherit Metab Dis 2012; 35:425-30.

19. Baldan A, Tagliati S, Saccomandi D, Brusaferro A, Busoli L, Scala $A$, et al. Assessment of lactose-free diet on the phalangeal bone mineral status in Italian adolescents affected by adult-type hypolactasia. Nutrient 2018; 10:558.

20. Demirdas S, van Spronsen FJ, Hollak CEM, van der Lee JH, Bisschop PH, vaz FM, et al. Micronutrients, essential fatty acids and bone health in phenylketonuria. Ann Nutr Metab 2017; 70:111-21. 